\title{
Isolation of Candida Species is an Important Clue for Suspecting Gastrointestinal Tract Perforation as a Cause of Empyema
}

\author{
Takashi Ishiguro ${ }^{1}$, Noboru Takayanagi ${ }^{1}$, Tomohiko Ikeya ${ }^{2}$, Hiroaki Yoshioka ${ }^{3}$, \\ Tsutomu Yanagisawa ${ }^{1}$, Eishin Hoshi ${ }^{2}$, Toshiko Hoshi ${ }^{4}$, Yutaka Sugita ${ }^{1}$ \\ and Yoshinori Kawabata ${ }^{5}$
}

\begin{abstract}
Background Empyema due to Candida species is a rare entity, and the significance of isolation of Candida species from the pleural effusion is not fully understood.

Objective To elucidate the clinical features of Candida empyema.

Methods We retrospectively reviewed the cases of 128 patients with culture-positive empyema.

Results These 128 patients included 7 whose cause of empyema was esophago- or gastropleural fistula. Empyema was due to Candida species in 5 of the 7 patients. Primary diseases of these 5 patients were spontaneous esophageal rupture in 3 patients, esophageal rupture due to lung cancer invasion in 1 patient, and gastric ulcer perforation in 1 patient. None of these 5 patients had esophageal candidiasis. Among the 121 other patients with empyema not due to esophago- or gastropleural fistula, no patient had empyema due to Candida.

Conclusion We believe that the empyema in these 5 patients was caused by normal commensal Candida species entering the pleural cavity when the fistula between the gastrointestinal tract and pleural cavity was formed. Isolation of Candida species can be an important clue for suspecting gastrointestinal tract perforation as a cause of empyema.
\end{abstract}

Key words: empyema, Candida species, esophageal rupture, stomach perforation

(Inter Med 49: 1957-1964, 2010)

(DOI: 10.2169/internalmedicine.49.3667)

\section{Introduction}

Empyema is defined as the presence of pus in the pleural cavity and represents an effusion containing a large number of polymorphonuclear leukocytes. The microbiology of empyema has changed over the last 50 years. In the preantibiotic era, Streptococcus pneumoniae accounted for $60 \%$ to $70 \%$ of cases and Streptococcus pyogenes for $10 \%$ to $15 \%$ of cases (1). S. pneumoniae now accounts for only $5 \%$ to $10 \%$ of cases, and many infections are mixed, with anaerobes present in $25 \%$ to $76 \%$ of empyemas either as the sole organisms or in combination with other aerobic or facultative organisms (2). Bartlett and Finegold (3) found that pleural empyema was caused by aerobic bacteria in $24 \%$, anaerobic bacteria in $35 \%$, and both aerobic and anaerobic bacteria in $41 \%$. The most common anaerobes isolated include the Bacteroides fragilis group, Prevotella species, Fusobacterium nucleatum, and Peptostreptococcus.

There are several mechanisms of empyema, and infection

\footnotetext{
${ }^{a}$ Department of Respiratory Medicine, Saitama Cardiovascular and Respiratory Center, Kumagaya, ${ }^{2}$ Department of Thoracic Surgery, Saitama Cardiovascular and Respiratory Center, Kumagaya, ${ }^{3}$ Department of Laboratory Medicine, Saitama Cardiovascular and Respiratory Center, Kumagaya, ${ }^{4}$ Department of Radiology, Saitama Cardiovascular and Respiratory Center, Kumagaya and ${ }^{5}$ Department of Pathology, Saitama Cardiovascular and Respiratory Center, Kumagaya

Received for publication March 16, 2010; Accepted for publication June 16, 2010

Correspondence to Dr. Takashi Ishiguro, ishiguro.takashi@ pref.saitama.lg.jp
} 
of the pleural cavity, most commonly following pneumonia, accounts for $40 \%$ to $60 \%$ of all empyemas. Thoracotomy, the next most common precursor to empyema, accounts for $20 \%$ of cases, with trauma accounting for $4 \%$ to $10 \%$ of cases. Less commonly, empyema can develop as a result of esophageal rupture, subdiaphragmatic spread, hematogenous seeding, and direct extension from head and neck infections (4).

Recently, we encountered a female patient with empyema whose causative microorganisms included Candida albicans. The patient complained of appetite loss and epigastralgia but did not have a history of vomiting followed by chest pain, nor did she have computed tomography (CT) findings suggestive of esophageal rupture such as esophageal thickening and extraluminal air in the mediastinum (5). Her pleural effusion amylase level at initial thoracentesis was normal, and esophageal rupture was not strongly indicated. Because Candida species were cultured from the pleural effusion, we speculated that gastrointestinal tract perforation might have caused the empyema. Gastroscopy and multi-detector row CT (MDCT) revealed a gastropleural fistula. On the basis of this experience, we investigated previous clinical reviews of Candida empyema, of which there have been a limited number $(6,7)$, and several sporadic case reports (8-13). These patients often suffered from esophageal rupture and showed mixed infection with oropharyngeal organisms (8-13). Thus, we hypothesized that isolation of Candida species from the pleural fluid of empyema might be a useful marker for suspecting esophago- or gastropleural communication. We therefore analyzed patients with Candida empyema in our hospital focusing specifically on pleural effusion findings in those patients with empyema due to gastrointestinal perforation to clarify our hypothesis.

\section{Materials and Methods}

Empyema was defined as pleural effusion with thick, purulent-appearing pleural fluid (14) or in which bacterial or fungal cultures are positive (15). We reviewed cases of culture-positive empyema occurring in our hospital from 1995 to 2009 and followed this with retrospective analysis of the subset of these cases in which gastrointestinal tract perforation resulted in empyema. We focused not only on isolation of Candida species from the pleural effusion but also on pleural effusion findings with a special interest in amylase value and the presence of yeasts, squamous epithelial cells, and ingested material, which have been known to be present in pleural effusion of patients with esophageal rupture resulting in empyema, and the results of which can be estimated early after obtaining specimens.

Pleural effusion samples were obtained by thoracentesis, and specimens were transported immediately to the laboratory in closed syringes or in tubes containing oxygen-free gas. Specimens were generally inoculated within 30 minutes of collection; however, exact records regarding transportation time were not available. Specimens were analyzed chemically and were inoculated onto GAM semisolid medium for aerobic, facultative, and anaerobic organisms. When microorganisms were cultured, we recorded the culture result as + . Specimens obtained on admission were also inoculated onto 5\% sheep's blood agar. Microorganism growth results in these cultures were recorded as follows: growth over the entire plate, $3+$; growth over two thirds of the plate, 2+; growth over one third of the plate, 1+; and growth over less than one third of the plate, light. Microorganisms isolated from prior tube thoracostomy for preexisting pneumothorax were assumed to be colonized within the chest tubes. Confirmation of Candida species was performed with CHROMagar Candida (CHROMagar Company, Paris, France), a selective and differential medium that allows selective isolation of yeasts and simultaneous identification by color reactions and colony morphology (16). Microorganisms including Candida species were regarded as the empyema pathogen when they grew from the pleural effusion sample obtained by thoracentesis performed on admission. For cytological study, pleural effusion was centrifuged at $3,000 \mathrm{rpm}$ for 30 minutes, and slides made from the centrifuged specimen were immediately fixed with $95 \%$ alcohol and stained using the appropriate stains for each case (Papanicolaou stain, Wright-Giemsa stain, and PAS stain). We reevaluated cytological specimens of pleural effusion for existence of squamous epithelial cells, yeasts, and ingested material, which were primarily evaluated semiquantitatively as follows: very large amount, 3+; large amount, 2+; per every visual field (magnification, $\times 10$ ), $1+$; per several visual fields (magnification, $\times 10$ ), \pm ; and none; -. Candida species were indicated when yeasts exhibiting single budding with pseudohyphae (constricted at the ends and attached like links of sausage) or true hyphae (parallel walls and unattached) were found. Ingested material was indicated when particles containing cell wall or skeletal muscle were found as reported previously (17).

Approval for this study was obtained from the hospital ethics subcommittee on human studies. Because the study was retrospective, the ethics subcommittee did not require patient informed consent for inclusion in the study. Statistical analysis was performed with a commercial software package (SPSS, Tokyo, Japan), and statistical significance was accepted at $\mathrm{p}<0.05$.

\section{Results}

From 1995 to 2009, 128 cases of empyema were recorded in our hospital in which causative microorganisms other than mycobacteria were cultured. Of these 128 empyema cases, $7(5.5 \%)$ were due to esophago- or gastropleural fistula. The remaining 121 cases were due to other causes unrelated to esophago- or gastropleural fistula.

\section{Empyema due to esophago- or gastropleural fistula}

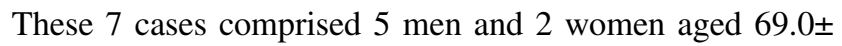
5.4 years (Table 1). Six of these patients were diagnosed as 
Table 1. Characteristics of Cases of Empyema due to Esophago- or Gastropleural Fistula

\begin{tabular}{|c|c|c|c|c|c|c|c|}
\hline Case & Age/Sex & Diagnosis & $\begin{array}{l}\text { Underlying } \\
\text { disease }\end{array}$ & Initial symptom & Fistula was confirmed by & Therapy & Outcome \\
\hline 1 & $61 / \mathrm{M}$ & $\begin{array}{l}\text { Spontaneous } \\
\text { esophageal rupture }\end{array}$ & $(-)$ & Epigastralgia after vomitting & $\begin{array}{l}\text { Gastroesophagography } \\
\text { with contrast medium }\end{array}$ & $\begin{array}{l}\text { Antibiotics, chest tube, } \\
\text { pleural cavity irrigation, } \\
\text { mediastinal drainage tube } \\
\text { and omentum patch, } \\
\text { esophageal stent }\end{array}$ & Alive \\
\hline 2 & $72 / \mathrm{M}$ & $\begin{array}{l}\text { Spontaneous } \\
\text { esophageal rupture }\end{array}$ & $(-)$ & Chest pain after vomitting & Thoracoscopy & $\begin{array}{c}\text { Antibiotics, chest tube, } \\
\text { pleural cavity irrigation, } \\
\text { T-tube }\end{array}$ & Alive \\
\hline 3 & $79 / \mathrm{M}$ & $\begin{array}{l}\text { Spontaneous } \\
\text { esophageal rupture }\end{array}$ & $(-)$ & Epigastralgia after vomitting & $\begin{array}{l}\text { Gastroesophagography } \\
\text { with contrast medium, } \\
\text { gastroscopy, MDCT }\end{array}$ & $\begin{array}{c}\text { Antibiotics, chest tube, } \\
\text { pleural cavity irrigation, } \\
\text { esophageal stent, } \\
\text { omentum patch }\end{array}$ & Alive \\
\hline 4 & $67 / \mathrm{M}$ & Esophageal rupture & $\begin{array}{l}\text { Esophageal } \\
\text { cancer }\end{array}$ & $\begin{array}{l}\text { Dyspnea, cough, and sputum } 6 \text { months } \\
\text { after radiotherapy and chemotherapy } \\
\text { for esophageal cancer }\end{array}$ & $\begin{array}{l}\text { Gastroesophagography } \\
\text { with contrast medium }\end{array}$ & Antibiotics, chest tube & Dead \\
\hline 5 & $66 / F$ & $\begin{array}{l}\text { Esophagopleural } \\
\text { fistula due to lung } \\
\text { cancer with } \\
\text { esophageal invasion }\end{array}$ & Lung cancer & $\begin{array}{c}\text { Fever after left pneumonectomy and } \\
\text { combined resection of esophageal } \\
\text { muscle layer }\end{array}$ & $\begin{array}{c}\text { MDCT and operative } \\
\text { observation }\end{array}$ & Antibiotics, fenestration & Alive \\
\hline 6 & $71 / \mathrm{M}$ & $\begin{array}{l}\text { Esophagopleural } \\
\text { fistula due to lung } \\
\text { cancer with } \\
\text { esophageal invasion }\end{array}$ & Lung cancer & Fever after initiation of chemotherapy & Gastroscopy & $\begin{array}{l}\text { Antibiotics, chest tube, } \\
\text { pleural cavity irrigation }\end{array}$ & Dead \\
\hline
\end{tabular}

MDCT; multidetector-row computed tomography

having esophagopleural fistula: spontaneous esophageal rupture $(n=3)$, esophagopleural fistula due to esophageal invasion of lung cancer $(n=2)$, and esophageal cancer rupture into the pleural cavity $(n=1)$. The remaining patient was diagnosed as having gastropleural fistula due to gastric ulcer perforation. Except for the 3 patients who were undergoing chemotherapy for esophageal cancer after surgery for lung cancer invasion to the esophagus or for lung cancer, there were no well-recognized factors such as malignancy, diabetes mellitus, acquired immune deficiency syndrome, or prior treatment with broad-spectrum antibiotics, steroids, or chemotherapy and/or radiation therapy that would predispose to fungal infection.

Initial presentation was epigastralgia or chest pain after vomiting in 3 patients with spontaneous esophageal rupture; fever after initiation of chemotherapy for lung cancer with invasion into the esophagus in 1 patient; dyspnea, cough, and sputum 6 months after radiotherapy and chemotherapy for esophageal cancer in 1 patient; and fever after left pneumonectomy and combined resection of the esophageal muscle layer in 1 patient. One patient with empyema due to gastric ulcer perforation developed fever when he was admitted to hospital by a local physician for appetite loss and anemia due to gastric ulcer.

Exudative pleural effusion by Light's criteria (18) was present in all 7 patients. Pleural effusion amylase values ranged from 22 to 40,400 U/L (Table 2). The patient with esophageal cancer rupture into the pleural cavity also had a normal pleural effusion amylase value, and the patient with gastric ulcer perforation had a normal amylase value on initial thoracentesis. The $\mathrm{pH}$ of the pleural effusion was not measured in these 7 patients.

Of these 7 cases, 5 (71.4\%) were due to Candida species (Table 2). Microorganisms cultured other than Candida species are shown in Table 2. Four of 5 cases showed mixed infection with Candida species, and 3 of 5 cases showed infection by more than 2 bacterial strains. On microscopic examination, yeasts indicating Candida species by morphology and squamous epithelial cells were found on admission in 5 Candida empyema patients (Table 2, Fig. 1). Ingested material was identified on admission in 3 cases of Candida empyema. Yeasts, squamous epithelial cells, and ingested material were not detected in Cases 4 and 5 .

In the 7 patients with esophago- or gastropleural fistula, helical CT showed esophageal thickening in 4 (57.1\%) patients and periesophageal fluid in $6(85.7 \%)$ patients (Ta- 
Table 2. Pleural Findings of Empyema due to Esophago- or Gastrointestinal Fistula

\begin{tabular}{|c|c|c|c|c|c|c|c|c|}
\hline Case & $\begin{array}{l}\text { Pleural Amy } \\
(\mathrm{U} / \mathrm{L})\end{array}$ & $\begin{array}{l}\text { Cultured microorganisms } \\
\text { other than Candida species } \\
\text { (growth) }\end{array}$ & $\begin{array}{l}\text { Candida species } \\
\text { (growth) }\end{array}$ & $\begin{array}{c}\text { Squamous } \\
\text { epithelial cells }\end{array}$ & Yeasts & $\begin{array}{l}\text { Ingested } \\
\text { material }\end{array}$ & Neutrophils & Comment \\
\hline 1 & 213 & $\begin{array}{l}\text { MRSA (2+), Enterococcus } \\
\text { faecalis (light), Klebsiella } \\
\text { pneumoniae (light) }\end{array}$ & $\begin{array}{c}\text { Candida albicans } \\
\text { (Light) }\end{array}$ & + & + & - & $3+$ & \\
\hline 2 & 40400 & $\begin{array}{l}\text { Streptococcus pneumoniae } \\
(1+), \text { Enterococcus species } \\
(1+), \text { Corynebacterium } \\
\text { species (light), } \\
\alpha-\text { Streptococcus normal } \\
\text { flora }(1+)\end{array}$ & $\begin{array}{l}\text { Candida albicans } \\
\text { (Light) }\end{array}$ & + & \pm & \pm & $3+$ & \\
\hline 3 & 8417 & $(-)$ & $\begin{array}{l}\text { Candida albicans } \\
\qquad(2+)\end{array}$ & + & $3+$ & + & $2+$ & \\
\hline 4 & 22 & $\begin{array}{l}\text { Streptococcus equinus }(1+) \\
\quad \text { Veillonella } \\
\text { specis }(1+)\end{array}$ & $(-)$ & - & - & - & - & \\
\hline 5 & 12571 & $\begin{array}{l}\text { Enterobacter aerogenes } \\
\qquad(3+), \\
\text { Enterococcus avium }(2+)\end{array}$ & $(-)$ & - & - & - & - & \\
\hline 6 & 1357 & $\begin{array}{c}\text { Eterococcus faecium }(1+) \text {, } \\
\alpha-\text { Streptococcus normal } \\
\text { flora }(1+), \text { Bacillus species } \\
(1+)\end{array}$ & $\begin{array}{c}\text { Candida grabrata } \\
\text { (Light) }\end{array}$ & \pm & $3+$ & + & $3+$ & $\begin{array}{l}\text { Estimated with PAS } \\
\text { stain }\end{array}$ \\
\hline 7 & 43 & Escherichia coli $(1+)$ & $\begin{array}{c}\text { Candida albicans } \\
\qquad(1+)\end{array}$ & + & \pm & + & $3+$ & Initial thoracentesis \\
\hline
\end{tabular}

- = not found $\pm=$ found per several visual fields; $+=$ found per every visual field; $2+=$ found in large amount; $3+=$ found in very large amount.

Abbreviations; MRSA; methicillin resistant staphylococcus aureus, Amy; amylase
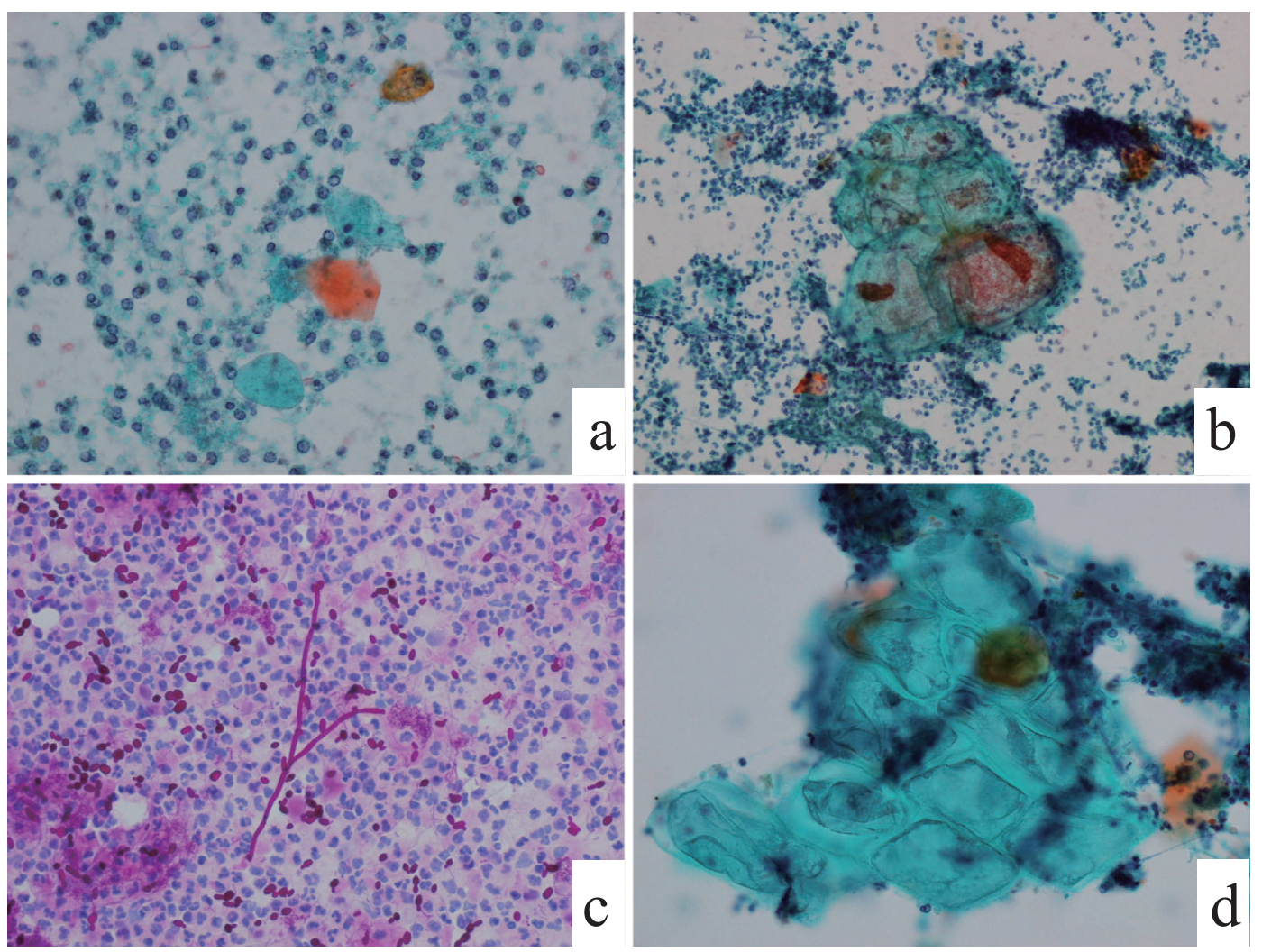

Figure 1. Cytological findings of pleural effusion with Candida empyema. Cytological findings showed squamous epithelial cells (a: $\times 40$, Papanicolaou stain), ingested materials with evident cell wall (b, d: $\times 40$, Papanicolaou stain), and yeasts indicating Candida species based on their shape (c: $\times 40$, PAS stain). 
Table 3. Characteristics of Pleural Effusion of 128 Patients with Empyema

\begin{tabular}{lcc}
\hline & $\begin{array}{c}\text { Empyema due to esophago- or } \\
\text { gastropleural fistula }(n=7)\end{array}$ & $\begin{array}{c}\text { Empyema not due to esophago- } \\
\text { or gastropleural fistula }(n=121)\end{array}$ \\
\hline Cytology & $(n=7)$ & $1(n=75)$ \\
Squamous epithelial cell & $5(71.4 \%)$ & $0(0 \%)$ \\
$\begin{array}{l}\text { Ingested material } \\
\text { yeasts indicated to be } \\
\text { Candida } \text { species }\end{array}$ & $4(57.1 \%)$ & $0(0 \%)$ \\
Culture & $4(57.1 \%)$ & $(n=121)$ \\
Candida species & $(n=7)$ & $0(0 \%)$ \\
\hline
\end{tabular}

Table 4. Chest Computed Tomography Findings on Admission

\begin{tabular}{|c|c|c|c|c|c|c|c|c|}
\hline \multirow[b]{2}{*}{ Case } & \multirow[b]{2}{*}{$\begin{array}{l}\text { Esophageal } \\
\text { thickening }\end{array}$} & \multirow[b]{2}{*}{$\begin{array}{c}\text { Periesophageal } \\
\text { fluid }\end{array}$} & \multicolumn{2}{|c|}{ Extraluminal air } & \multirow{2}{*}{$\begin{array}{c}\text { Pleural effusion } \\
\text { Side (R/L/B) }\end{array}$} & \multicolumn{3}{|c|}{ The site of perforation is visible } \\
\hline & & & Mediastinal & Pleural cavity & & Helical plain CT & $\begin{array}{c}\text { Helical } \\
\text { enhanced CT }\end{array}$ & MDCT \\
\hline 1 & + & + & + & + & $\mathrm{B}(\mathrm{R}>>\mathrm{L})$ & + & N.D & N.D \\
\hline 2 & + & + & - & + & $\mathrm{L}$ & + & N.D & N.D \\
\hline 3 & + & - & - & $\# 1$ & $\# 1$ & N.D & N.D & + \\
\hline 4 & + & + & - & + & $\mathrm{B}(\mathrm{R}>>\mathrm{L})$ & N.D & + & N.D \\
\hline 5 & - & + & - & $\# 2$ & $\mathrm{~B}(\mathrm{~L}>>\mathrm{R})$ & - & - & + \\
\hline 6 & - & + & - & + & $\mathrm{R}$ & N.D & + & N.D \\
\hline 7 & - & + & - & + & $\mathrm{B}(\mathrm{L}>>\mathrm{R})$ & N.D & N.D & - \\
\hline
\end{tabular}

MDCT; multidetector-row computed tomography, Not estimated because chest tube had been inserted (\#1), and post pneumonectomy (\#2) Abbreviations: L; light, R; right, B; bilateral, N.D; not determined

ble 3). Extraluminal air was detected in the mediastinum in $1(14.3 \%)$ of the 7 patients and in the pleural cavity in all 5 (100\%) patients with Candida empyema. A chest tube had been already inserted in the other 2 patients when chest CT was performed, and it could not be determined if extraluminal air had been present in the pleural cavity of these patients. Pleural effusion was found in the right in 1 , left in 1 , and bilaterally in 4 of 6 patients. Laterality of the pleural effusion could not be estimated in 1 patient because the patient had received a left pneumonectomy. The site of perforation was visible in all 3 patients who underwent MDCT. The site of perforation was also visible in $2(66.7 \%)$ of 3 patients on helical plain CT and $2(100 \%)$ of 2 patients undergoing helical enhanced CT on our reevaluation of this study; however, these findings were missed and not confirmed at the original interpretation of the CTs.

Diagnosis of gastrointestinal perforation was confirmed by gastroesophagography with contrast medium in 3 cases, thoracoscopy in 1 case, gastroscopy in 3 cases, MDCT in 3 cases, and operative findings in 1 case. Gastroscopy confirmed the absence of esophageal candidiasis in 5 cases.

All 7 patients underwent chest tube insertion and irrigation of the pleural cavity with saline or povidone iodine (Table 1). Mediastinal drainage was performed in 1 patient. Antibiotics were administered in all 7 patients; however, an antifungal agent was administered in only 1 patient for 3 days. An esophageal stent was inserted in 2 patients, and an esophageal T-tube and a mediastinal drainage tube was in- serted in 1 patient each. An omentum patch was placed at the perforation site in 3 patients, and fenestration was performed in 1 patient.

Four of the 6 patients with esophagopleural fistula recovered (Table 1). One patient with esophagopleural fistula due to esophageal invasion of lung cancer, and 1 patient with esophagopleural fistula due to esophageal cancer rupture died. The patient with gastropleural fistula due to gastric ulcer perforation died from myocardial infarction 28 days after surgery.

\section{Empyema unrelated to esophago- or gastropleural fistula}

Biochemical analysis was performed in 78 of the 121 patients with empyema not due to esophago- or gastropleural fistula (Table 4), and all patients had exudative pleural effusion by Light's criteria (18). No patients yielded Candida species. All patients had a pleural effusion amylase value below $90 \mathrm{U} / \mathrm{L}$ (median, $32 \mathrm{U} / \mathrm{L}$; range, 0-90 U/L), and this value was significantly lower than that of patients with esophago- or gastropleural fistula $(\mathrm{p}=0.002)$. The $\mathrm{pH}$ of the pleural effusion was not measured in any patient. Microscopic examination of the pleural effusion of 75 of these 121 patients revealed neither ingested material nor yeasts indicating Candida species by morphology. Squamous epithelial cells with distinct nuclei were seen in only $1(1.3 \%)$ of these 75 patients. This patient did not have gastrointestinal perforation but developed empyema with pneumothorax due 
to a bronchopleural fistula resulting from perforation of a lung abscess into the pleural cavity. The resected lung showed squamous metaplasia of the lung.

Finally, sensitivity and specificity of detection of pleural effusion yeasts for diagnosing Candida empyema were both $100 \%$. However, sensitivity and specificity of pleural effusion findings for diagnosing esophago- or gastropleural fistula were as follows: elevated amylase value (>90 U/L): sensitivity $71.4 \%$, specificity $100 \%$; presence of squamous epithelial cells: sensitivity $71.4 \%$, specificity $99.2 \%$; presence of microscopic ingested material: sensitivity $57.1 \%$, specificity $100 \%$; presence of microscopic Candida species: sensitivity $71.4 \%$, specificity $100 \%$; and positive culture of Candida species: sensitivity $71.4 \%$, specificity $100 \%$.

\section{Discussion}

Retrospective analysis of 128 cases of culture-positive empyema revealed 7 patients with empyema due to esophago- or gastropleural fistula. Candida empyema was found in 5 of these patients, all of whom had esophago- or gastropleural fistula as the cause of empyema. Culture of Candida species requires several days for identification. Identification of yeasts indicated to be Candida species microscopically showed $100 \%$ sensitivity and specificity for Candida empyema, and this finding may expedite the diagnosis. However, the sensitivity of identification of yeasts for diagnosing esophago- or gastropleural fistula was no better than $71.4 \%$ ( 5 of the 7 patients). Therefore, absence of yeasts cannot rule out esophago- or gastropleural fistula.

\section{Empyema due to esophagopleural fistula}

Esophageal rupture is a life-threatening condition that may rapidly progress to fulminant mediastinitis and septic shock, and diagnosis should not be delayed. Epigastralgia or chest pain after vomiting was found initially in all patients with spontaneous esophageal rupture. Fever, dyspnea, cough, and sputum occurred in 1 patient each after initiation of chemotherapy, radiotherapy, or pneumonectomy with combined resection of the esophageal muscle layer. Such clinical histories may be useful for suspecting esophageal rupture.

CT is an efficient method for diagnosing esophageal rupture. The site of perforation was visible in a high proportion of patients in the present study who underwent CT or MDCT. White et al (19) found that CT was useful for diagnosing patients without typical symptoms and have suggested useful findings for esophageal rupture to be the presence of esophageal thickening, periesophageal fluid, and extraluminal air. These findings were also found in $16.7 \%$ to $100 \%$ of our patients with empyema due to esophagopleural fistula. However, they were not specific for empyema due to esophagopleural fistula. For example, the differential diagnosis of extraluminal air in the pleural cavity includes bronchopleural fistula from pulmonary infections, spontaneous pneumothorax with pleural effusion, trauma (iatrogenic or non-iatrogenic), the presence of gas-forming organisms in the pleural space, and rupture of the esophagus into the pleural space.

Examination of the pleural fluid is helpful in suggesting the diagnosis of esophageal rupture. Pleural fluid in such cases is characterized by a high amylase level, the presence of squamous epithelial cells, low $\mathrm{pH}$, and the occasional presence of ingested material. The level of the pleural effusion amylase (derived from the salivary glands) is elevated in most patients (20), with the exception of a rare case of sicca syndrome in which the amylase level was normal (21). Pleural effusion amylase values in our patients with empyema not due to esophago- or gastropleural fistula were consistently $<90 \mathrm{U} / \mathrm{L}$. Therefore, elevated pleural effusion amylase level $>90$ U/L may be a useful marker of esophageal rupture. However, $1(16.6 \%)$ of our 6 patients with esophagopleural fistula had a normal pleural fluid amylase level; thus, a normal pleural effusion amylase value can not rule out the possibility of esophageal rupture.

Pleural fluid $\mathrm{pH}$ was not measured in our study; however, a pleural fluid $\mathrm{pH}<7.0$ may increase the likelihood that the patient has an esophageal rupture (22), so $\mathrm{pH}$ should be measured with dipstick or $\mathrm{pH}$ indicator paper if pleural fluids cannot analyzed with a blood gas machine. Patients with severe infections of the pleural space and an intact esophagus frequently have a low pleural fluid $\mathrm{pH}$, so pleural $\mathrm{pH}$ alone should not be used as an indicator of esophageal rupture.

Eriksen (23) reported the presence of squamous epithelial cells in the pleural fluid of all 14 patients with esophageal rupture. However, no reports indicate whether squamous epithelial cells are seen in patients with empyema not due to esophagopleural fistula. Squamous epithelial cells were present in the pleural fluid of $4(66.7 \%)$ of our 6 patients with esophagopleural fistula but were seen in only 1 patient (1.33\%) with empyema without esophago- or gastropleural fistula. This patient, a 62-year-old man who developed pneumothorax and empyema due to perforation of a lung abscess into the pleural cavity, underwent partial lung resection and chest tube insertion for bronchopleural fistula. Gastrointestinal perforation was not found. The squamous epithelial cells had distinct nuclei and were not thought to be derived from the skin (23). We investigated his resected lung tissue and observed squamous metaplasia. We believe that squamous metaplasia cells from the lung, which developed in response to infection, had entered the pleural cavity. Alcaligenes species, which was cultured from the patient's pleural effusion, can be found in respiratory secretions (24). Therefore, cytological findings should be carefully evaluated in cases of empyema, with esophageal rupture being considered as a potential cause of the empyema.

Identification of ingested material in pleural effusion is clearly diagnostic of esophagopleural fistula, but such material is not always present. We found ingested material by microscopic examination in $4(66.7 \%)$ of 6 patients. Usefulness of cytologic findings for detecting ingested material has been reported (17), and we found that ingested material can 
be detected to a high degree in cases of esophagopleural fistula.

\section{Empyema due to gastropleural fistula}

Reports of gastric ulcer as a cause of empyema are limited, and the precise characteristics are not yet known (25). Other than esophageal rupture and pancreaticopleural fistulas, it is unusual for abdominal organs to be associated with nontraumatic pulmonary or pleural communication. A limited number of previous reports have revealed the occurrence of gastro-bronchial fistulas, diaphragmatic hernia (26), and complications of a subphrenic abscess (27). In our patient (Case 5), the upper portion of the stomach was strongly adhered to the diaphragm, and the gastric ulcer perforation communicated with the pleural cavity through a diaphragmatic defect. Brandstetter et al (25) reported a 63year-old man with empyema due to a gastric ulcer that had formed a gastropleural fistula. The patient developed illdefined left shoulder pain of unknown origin that was treated with ibuprofen and hydromorphone hydrochloride and complained of intermittent nausea and vomiting for 2 months. Our patient was diagnosed as having a gastric ulcer with evident anemia by a local physician. Such clinical history information may serve to suspect gastric ulcer as the possible cause of empyema. Chest CT in this patient showed periesophageal fluid and extraluminal air in the pleural cavity, but esophageal thickening or extraluminal air in the mediastinum was not seen. The perforation site was visible by MDCT. Brandstetter et al. also suggested that pleural effusion with extremely acidic exudates and low glucose and elevated bilirubin levels as compared to blood levels may suggest gastropleural fistula (25). We did not measure pleural bilirubin value or $\mathrm{pH}$, but our patient did not show bilious pleural effusion. Squamous epithelial cells were found in the pleural effusion of this patient, indicating that the presence of such cells is useful for suspecting gastropleural fistula. The patient's pleural effusion amylase value was normal.

\section{Isolation of Candida species in the pleural effusion}

Candida species are normal commensals of humans, commonly found on skin, throughout the entire gastrointestinal tract, in expectorated sputum, and in the female genital tract. Ko et al (6) have suggested the following diagnostic criteria of fungal empyema to be isolation of fungal species from thoracentesis fluid of the exudates type, significant signs of infection such as fever or leukocytosis, and isolation of the same fungus from pleural fluid and other specimens such as blood, sputum, or surgical wound cultures that show evidence of tissue invasion. However, isolation of Candida species in the present study was limited only to the cases of empyema with esophago- or gastropleural fistula. Thus, isolation of Candida species cannot be regarded as contamination, and we believed Candida species to be the pathogen causing empyema when they grew from the pleural effusion obtained by thoracentesis performed on admission. None of the 7 patients in the present study had esophageal candidiasis, and we think that normal commensal Candida species entered the pleural cavity through the gastropleural fistula.

To our knowledge, Candida empyema is rare. Alfageme et al (4) reported no instances of Candida empyema in 82 patients. In our 128 patients, Candida species was isolated from pleural effusion only in the patients with esophago- or gastropleural fistula, indicating that esophageal or gastric perforation should be suspected as a potential cause of empyema when Candida empyema is encountered. Candida empyema has been reported as a complication of surgery, as a subdiaphragmatic infection, and as being spread hematogenously $(6,28)$. Although the patients in the present study did not have these disorders, they should also be suspected. However, pleural effusion in 2 patients (33.3\%) with esophageal rupture did not yield Candida species, and there are a few reports of empyema due to esophageal rupture in which Candida species were not present in the pleural effusion (29). Therefore, the absence of Candida species in pleural effusion cannot rule out the probability of esophagoor gastropleural fistula as a cause of the empyema. In addition, yeasts indicated to be Candida species were found microscopically in 5 of our 7 patients with empyema due to esophago- or gastropleural fistula but in none of the 121 patients with empyema not due to gastrointestinal perforation. Microscopic findings of yeasts can be obtained rapidly; therefore, identification of yeasts in the pleural effusion specimen may point to an early diagnosis of esophago- or gastropleural fistula as the cause of empyema.

Almoosa et al (13) have suggested isolation of Lactobacillus species to be an important clue for suspecting esophageal rupture because these bacteria colonize the gastrointestinal tract. However, we did not isolate Lactobacillus species in any of our patients.

Administration of antifungal agents in patients with esophageal rupture or stomach perforation, and especially in those empyema whose pleural effusion has yielded Candida species, is an additional problem. Ko et al (6) reported that except for 1 patient who underwent surgical intervention, all 18 of their patients with fungal empyema who did not receive antifungal therapy died. It is postulated that patients infected with a Candida species should receive an appropriate antifungal drug for 2 weeks after the resolution of signs and symptoms of infection (24). In our patients, the significance of identification of Candida species in the pleural effusion was underestimated at first, so antifungal drugs were not administered or were administered only for a short period, and 3 of our 7 patients died. Those 3 patients had undergone chest tube drainage with irrigation of pleural cavity and antibiotics administration. One received fluconazole for 3 days and underwent surgery for an omentum patch but died of myocardial infarction 28 days after surgery. Chatterjee et al (9) reported a patient with esophageal rupture with empyema due to Candida tropicalis who improved not with antifungal drugs but with surgery. In such cases, treatment other than antifungal therapy may be effective. However, it 
is not clear whether isolation of Candida species indicates Candida infection or is simply a marker of aspiration of gastrointestinal content into the pleural cavity. Additional data should be accumulated to clarify whether antifungal treatment should be performed in cases of empyema due to gastrointestinal tract perforation.

We were limited in our investigation of cases of empyema due to esophago- or gastropleural fistula because it took from 1 to 11 days for the patient to be transferred to our hospital; therefore, none of our patients can be regarded as being at an early stage after onset. Future study is necessary to determine whether Candida species can be isolated at an early stage in patients with empyema due to gastrointestinal tract perforation.

In conclusion, for patients with empyema due to esophago- or gastropleural fistula, the respiratory physician should suspect the cause of the empyema to be gastrointestinal perforation on the basis of patient history, radiological findings, and laboratory findings. In pleural fluid, the amylase level and the presence of squamous epithelial cells, a low $\mathrm{pH}$, and sometimes ingested material have been useful markers of esophagopleural fistula. Microscopic identification of yeasts indicated to be Candida species by morphology and isolation of Candida species in the pleural fluid should also be considered as additional diagnostic clues.

\section{Acknowledgement}

We thank Mitsumasa Funabashi of the Department of Laboratory Medicine, Saitama Cardiovascular and Respiratory Center, for his detailed comments on the cytological findings. We also thank our colleagues of the Department of Respiratory Medicine, Saitama Cardiovascular and Respiratory Center, Tsugumi Samejima, Makoto Hayashi, Koichiro Yoneda, Yousuke Miyahara, Daido Tokunaga, and Kazuyoshi Kurashima, for their cooperation in the diagnosis and treatment of the patients.

\section{References}

1. Finland M, Barnes MW. Changing ecology of acute bacterial empyema: occurrence and mortality at Boston City Hospital during 12 selected years from 1935-1972. J Infect Dis 137: 274-291, 1978.

2. Civen R, Jousimies-Somer H, Marina M, Borenstein L, Shah H, Finegold SM. A retrospective review of cases of anaerobic empyema and update of bacteriology. Clin Infect Dis 20: S224-S229, 1995.

3. Bartlett JG, Finegold SM. Anaerobic infections of the lung and pleural space. Am Rev Respir Dis 110: 56-77, 1974.

4. Alfageme I, Munoz F, Pena N, Umbria S. Empyema of the thorax in adults. Etiology, microbiologic findings, and management. Chest 103: 839-843, 1993.

5. Backer CL, LoCicero J 3rd, Hartz RS, Donaldson JS, Shields T. Computed tomography in patients with esophageal perforation. Chest 98: 1078-1080, 1990.

6. Ko SC, Chen KY, Hsueh PR, Luh KT, Yang PC. Fungal empyema thoracis: an emerging clinical entity. Chest 117: 1672-1678, 2000.

7. Varghase JC, Hahn PF, Harisinghani MG, et al. Fungus-infected fluid collections in thorax or abdomen: effectiveness of percutaneous catheter drainage. Radiology 236: 730-738, 2005.

8. Baradkar VP, Mathur M, Kulkarni SD, Kumar S. Thoracic empyema due to Candida albicans. Indian J Pathol Microbiol 512: 286-288, 2008.

9. Chatterjee B, Arya M, Gupta P, Sahoo SP, Chakrabarti A. Case Report: Empyema thoracis with Candida tropicals. Indian J Med Microbiol 17: 189-190, 1999.

10. Sharma JK, Marrie TJ. Explosive pleuritis. Can J Infect Dis 12: 104-107, 2001.

11. Hull JH, Kendall A, Lofts F. Fungal empyema thoracis complicating treatment of esophageal carcinoma. Postgrad Med J 80: 154, 2004.

12. Lucas CE, Splittgerber F, Ledgerwood A. Conservative therapy for missed esophageal perforation after blunt trauma. Am J Emerg Med 4: 520-522, 1986.

13. Almoosa KF, Wardell N, Javaheri S. Elevated glucose in pleural effusion: an early clue to esophageal perforation. Chest 131: 15671569, 2007.

14. Light RW. Parapneumonic effusions and empyema. In: Pleural Diseases. 5th edition. Light RW, Ed. Lippincott Williams \& Wilkins, Philadelphia, 2007: 179-210.

15. Vianna NJ. Nontuberculous bacterial empyema in patients with and without underlying diseases. JAMA 215: 69-75, 1971.

16. Odds FC, Bernaerts R. CHROMagar Candida, a new differential isolation medium for presumptive identification of clinically important Candida species. J Clin Microbiol 32: 1923-1929, 1994.

17. Drury M, Anderson W, Heffner JE. Diagnostic value of pleural fluid cytology in occult Boerhaave's syndrome. Chest 102: 976978, 1992.

18. Light RW. Clinical manifestations and useful tests. In: Pleural Diseases. 5th edition. Light RW, Ed. Lippincott Williams \& Wilkins, Philadelphia, 2007: 73-108.

19. White CS, Templeton PA, Attar S. Esophageal perforation: CT findings. AJR Am J Roentgenol 160: 767-770, 1993.

20. Sherr HP, Light RW, Merson MH, Wolf RO, Taylor LL, Hendrix TR. Origin of pleural fluid amylase in esophageal rupture. Ann Intern Med 76: 985-986, 1972.

21. Faling LJ, Pugatch RD, Robbins AH. The diagnosis of unsuspected esophageal perforation by computed tomography. Am J Med Sci 281: 31-34, 1981.

22. Light RW. Pleural effusion secondary to diseases of the gastrointestinal tract. In: Pleural Diseases. 5th edition. Light RW, Ed. Lippincott Williams \& Wilkins, Philadelphia, 2007: 252-264.

23. Eriksen KR. Oesophagopleural fistula diagnosed by microscopic examination of pleural fluid. Acta Chir Scand 128: 771-777, 1964.

24. Steinberg JP, Rio CD. Other gram-negative and gram variable bacilli. In: Mandell, Douglas, and Bennett's Principles and Practice of Infectious Disease. 6th ed. Mandell GL, Bennet JE, Dolin R, Eds. Churchill Livingstone, Philadelphia, 2005: 2751-2769.

25. Brandstetter RD, Klass SC, Gutherz P, Neglia W, Pinals DJ. Pleural effusion due to communicating gastric ulcer. N Y State J Med 85: 706-707, 1985.

26. Mason LB. Subphrenic abscess. Report of a case with fistulous connections to the stomach, colon and bronchus. Am Surg 31: 278-280, 1965.

27. Hathirat S, Renzatti AD Jr. Gastrobronchial fistula complicating subphrenic abscess. A case report. Am Rev Respir Dis 99: 581$584,1969$.

28. Septimus E. Pleural effusion and empyema. In: Mandell, Douglas, and Bennett's Principles and Practice of Infectious Disease. 6th ed. Mandell GL, Bennet JE, Dolin R, Eds. Churchill Livingstone, Philadelphia, 2005: 845-855.

29. Brown RH Jr, Cohen PS. Nonsurgical management of spontaneous esophageal perforation. JAMA 240: 140-142, 1978.

(C) 2010 The Japanese Society of Internal Medicine http://www.naika.or.jp/imindex.html 